\title{
The influence of digital economy on the upgrading of industrial structure
}

\author{
Siyu $\mathrm{Liu}^{1, *}$ \\ ${ }^{1}$ Beijing Jiaotong University, School of Economics and Management, Haidian, Beijing, China
}

\begin{abstract}
Digital economy is an important starting point for China's high-quality economic development, which may have an impact on the level of industrial structure. This paper calculates the development level of digital economy by entropy weight method, selects the relevant data of 31 provinces and cities in China from 2012 to 2019, and uses the method of empirical test to analyze the impact of the development of digital economy on the upgrading of China's industrial structure. The result shows that the development of digital economy can promote the upgrading of China's overall industrial structure, which is significant at the level of $1 \%$. Further research shows that the development of digital economy has regional heterogeneity on the upgrading of industrial structure in the eastern, central and western regions of China. The research of this paper has important practical significance for the high-quality development of China's economy.
\end{abstract}

\section{Introduction}

With the advent of Industry 4.0 era, digital technologies such as blockchain, big data and cloud computing have become the emerging technology trend of economic development, and human society is gradually entering the era of digital economy. China is also vigorously developing digital economy, and gradually narrowing the digital gap with developed countries by taking advantage of digital economy. In the post-epidemic era, the digital economy provides a strong driving force for the survival and development of enterprises.

With the continuous development of digital economy, the theoretical research on digital economy has been gradually enriched. In recent years, many domestic scholars have been studying the mechanism of the effect of digital economy.

The research on digital economy is very extensive. For example, Zhao Xisan ${ }^{[1]}$ (2017) proposed that the digital economy promotes China's manufacturing industry to speed up towards the high end of the global value chain . Jing Wenjun et al. ${ }^{[2]}$ (2019) pointed out that the rapid development of digital economy can provide better matching mechanism and innovation incentive for the construction of China's modern economic system. Jia Hui et al. ${ }^{[3]}$ (2020) demonstrated that in the post-epidemic era, the new network consumption pattern based on the tertiary industry has opened up a new space for the development of digital economy, which becomes an important growth point of economic development in China.

In recent two years, many scholars have studied the impact of digital economy on manufacturing industry. Cao Zhengyong ${ }^{[4]}$ (2018) pointed out that under the background of digital economy, we should strengthen the construction of network infrastructure, the construction of industrial information security system, and the support of qualified personnel to promote the digital transformation and the upgrading of manufacturing industry. Shen Yunhong et al. ${ }^{[5]}$ (2020) subdivided the level of digital economy into the level of digital infrastructure construction, the level of digital industry development and the level of digital technology innovation and scientific research, and studied the influence of three aspects on the optimization and upgrading of the industrial structure of traditional manufacturing industry. The results show that the three aspects can optimize the industrial structure of manufacturing industry, and the level of digital technology innovation and scientific research plays the most positive role.

At present, the research on the macro impact of digital economy on the upgrading of industrial structure is still in its infancy, so this paper studies this issue, explores the impact of digital economy on the upgrading of industrial structure through theoretical analysis and empirical analysis, and further studies the impact in different regions. The marginal contribution of this paper is to divide the development level of digital economy into three types: basic type, resource-based type and technology type. This division describes the development level of digital economy systematically and comprehensively. Through theoretical analysis and empirical research, this paper provides a strong support for the further development of digital economy and the promotion of industrial structure upgrading.

\footnotetext{
* Siyu Liu: 20120664@bjtu.edu.cn
} 


\section{Materials and Methods}

\subsection{Theoretical analysis and hypothesis development}

According to the white paper on the development and employment of China's digital economy, digital economy is a new economic form which takes the information network as the carrier, integrates the innovative digital technology with the real economy, and continuously improves the digitization and intelligence level of traditional industries.

The development of digital economy is inseparable from the rapid development of infrastructure. The rapid development of information and communication industry provides digital technology, products and services for the digital development of other industries. The prompt growth of the Internet provides a resource guarantee for the development of digital economy. China's Internet industry is in the stage of vigorous development, and its application is constantly infiltrating in various industries. Moreover, scientific and technological research and development provides technical support for the development of digital economy. Especially in today's post-epidemic period, the development of artificial intelligence provides great convenience for our lives. Digital economy has been providing impetus for the development and reform of various industries in China.

Industrial convergence is the driving force for the continuous development and innovation of digital technology, and the output and efficiency of departments integrating digital economy will also be improved. At the same time, the digital transformation of the real economy is proceeding smoothly, in which the service field is the leader of the digital transformation, and many enterprises are building platforms through social networks such as the Internet. Through the integration of digital technology, many applications and mini programs emerge, which not only provide convenience for consumers, but also improve the production and operation efficiency of enterprises. Through the digital transformation, the e-commerce industry is booming, and the online retail sales are rising rapidly.

Generally speaking, the development of digital economy will promote the development and innovation of industries, promote the deep integration among industries, and realize the upgrading of industrial structure. Therefore, this paper puts forward the hypothesis.

Hypothesis: the development of digital economy can promote the upgrading of industrial structure.

\subsection{Variable description}

\subsubsection{Dependent variable}

Industrial structure level (STR): The industrial structure level coefficient is introduced to explain the industrial structure level of each province (city), the formula is as follows:
Str $=\sum_{i=1}^{3} q_{i} \times i=q_{1} \times 1+q_{2} \times 2+q_{3} \times 3$

$q_{i}$ is the proportion of the $\mathrm{i}$ industry.

The ratio of gross domestic product of tertiary industry to gross domestic product of secondary industry (RTS) is selected as the dependent variable for robustness test.

\subsubsection{Independent variable}

The independent variable of this paper is the development level of digital economy (Dig), but there is no normative index to describe the development level of digital economy. Therefore, nine indicators were selected to measure the development level of digital economy from three dimensions: basic digital economy development level, resource-based digital economy development level and technical digital economy development level. Referring to the calculation method of Zhang Xueling et al. ${ }^{[6]}$ (2017) on digital economy, the initial value is standardized and the entropy weight method is used to calculate the development level of digital economy..

Considering the integrity and availability of data, the development level of basic digital economy is calculated based on the length of optical cable lines, the number of employees in information transmission, software and information technology services, and the popularization rate of mobile telephone; the development level of resource-based digital economy is calculated by the number of Internet domain names and web pages; the development level of technical digital economy is calculated based on the full-time equivalent of R\&D personnel, the expenditure on $R \& D$, the $R \& D$ projects and the number of inventions of industrial enterprises above designated size.

\subsubsection{Control variables}

Economic development level (PGDP): Use per capita GDP to reflect the economic development level of an area. When the economy develops to a certain level, it will reverse the industrial structure and promote the upgrading and optimization of the industrial structure.

Economic Openness (Open): It is calculated by the ratio of the total import and export volume of goods of each province (converted by the average exchange rate between RMB and US dollar over the years) to GDP. The import and export of goods include new machinery and equipment. The introduction of high-tech equipment will promote the upgrading of the industrial structure of the area. The more the total import and export volume of goods, the greater the economic openness of the area.

Government intervention (Gov): The government intervention function is measured by the ratio of local government's general budget expenditure to local GDP. The fiscal expenditure of local government plays an important role in its market. The more fiscal expenditure, the stronger the compensation effect of the local government on the spontaneous regulation of the market, 
and can also effectively promote the upgrading of industrial structure.

Human capital (Hum): The average years of education index is used to measure the level of human capital. The higher the level of human capital in an area, the higher the quality of labor force in the area, which can promote the upgrading of industrial structure. The specific calculation formula is as follows:

Hum $=\frac{\text { Hum }_{1} \times 6+\text { Hum }_{2} \times 9+\text { Hum }_{3} \times 12+\text { Hum }_{4} \times 16}{\text { Hum }_{5}}$

$H_{u m}$ represents the population of primary school education, $\mathrm{Hum}_{2}$ represents the population of junior high school education, $\mathrm{Hum}_{3}$ represents the population of high school education level, $\mathrm{Hum}_{4}$ represents the population of junior college and above, and $\mathrm{Hum}_{5}$ represents the population aged six and over.

\subsection{Empirical model}

According to the theoretical analysis of this paper, the following multivariate linear empirical model is constructed:

$$
S t r_{\mathrm{it}}=\alpha_{0}+\alpha_{1} \text { Dig }_{i t}+\sum_{j=1}^{4} \beta_{j} \text { Control }_{j, i t}+\varepsilon_{i t}
$$

The subscripts $\mathrm{i}$ and $\mathrm{t}$ represent the province (city) and year respectively, and $\mathrm{j}$ represents the $\mathrm{j}$-th control variable, and $\varepsilon_{i t}$ represents the random disturbance term independent of the dependent variable.

\subsection{Data sources and descriptive statistics}

The data of this paper comes from China Stock Market \& Accounting Research Database and China Statistical Yearbook. Through further calculation and processing, the variables of 31 provinces and cities in China from 2012 to 2019 are obtained. The descriptive statistical characteristics are shown in the table below.

Table 1. Descriptive statistics

\begin{tabular}{cccccc}
\hline Variables & $\mathrm{N}$ & Mean & SD & Min & Max \\
\hline Dig & 248 & 2.893 & 2.381 & 0.582 & 20.45 \\
Str & 248 & 2.377 & 0.125 & 2.182 & 2.832 \\
RTS & 248 & 1.218 & 0.664 & 0.549 & 5.169 \\
Pgdp & 248 & 55840 & 26478 & 19710 & 164220 \\
Open & 248 & 0.259 & 0.287 & 0.0127 & 1.44 \\
Gov & 248 & 0.285 & 0.213 & 0.118 & 1.379 \\
Hum & 248 & 9.1 & 1.147 & 4.222 & 12.68 \\
\hline
\end{tabular}

From the table 1, it can be seen that the minimum value of the development level of digital economy is 0.582 , the maximum value is 20.45 , and the standard deviation is 2.381. It shows that there are great differences in the development level of digital economy in different areas and in different years. Since the level of industrial structure does not exceed 3 , so the gap is also large.

\section{Results \& Discussion}

\subsection{Basic regression analysis}

The panel data samples selected in this paper are used for fixed effect model regression and random effect model regression, and robust Hausman test is used to select the appropriate model for analysis according to the results.

The $p$ value of robust Hausman test of basic regression results is 0.0191 , which indicates that the estimation result of fixed effect model is the best and the most robust.

From the regression result of column 1 in Table 2, the coefficient of the development level of digital economy passed the $1 \%$ significance level test, which shows that the development level of digital economy has a promoting effect on the upgrading of industrial structure, and the hypothesis has been verified.

The coefficient of economic openness is significantly positive at the level of $1 \%$, which indicates that there is a positive relationship between economic openness and the upgrading of industrial structure. The possible reason is that the introduction and application of science and technology capital will improve the innovation efficiency and development of industries, and then promote the upgrading of industrial structure. The coefficient of government intervention is significantly positive at the level of $1 \%$, which indicates that the government's economic intervention can effectively promote the upgrading of the industrial structure

Table 2. Basic regression results and robustness test results

\begin{tabular}{cccc}
\hline & $(1)$ & $(2)$ & $(3)$ \\
\hline \multirow{2}{*}{ VARIABLES } & $\mathrm{FE}$ & $\mathrm{RE}$ & $\mathrm{FE}$ \\
& $\mathrm{Str}$ & $\mathrm{Str}$ & $\mathrm{RTS}$ \\
\hline \multirow{2}{*}{ Dig } & $0.00510^{* * *}$ & $0.00710^{* * *}$ & $0.0139^{* *}$ \\
& $(0.00122)$ & $(0.00116)$ & $(0.00584)$ \\
Pgdp & $3.12 \mathrm{e}-06^{* * *}$ & $2.29 \mathrm{e}-06^{* * *}$ & $1.21 \mathrm{e}-05^{* * *}$ \\
& $(3.39 \mathrm{e}-07)$ & $(2.39 \mathrm{e}-07)$ & $(1.62 \mathrm{e}-06)$ \\
Open & $0.223^{* * *}$ & $0.134^{* * *}$ & 0.0744 \\
& $(0.0441)$ & $(0.0232)$ & $(0.210)$ \\
Gov & $0.908^{* * *}$ & $0.355^{* * *}$ & $4.677^{* * *}$ \\
& $(0.114)$ & $(0.0428)$ & $(0.545)$ \\
Hum & $0.0290^{* *}$ & $0.0501^{* * *}$ & 0.0886 \\
& $(0.0122)$ & $(0.00850)$ & $(0.0583)$ \\
Constant & $1.608^{* * *}$ & $1.637^{* * *}$ & $-1.656^{* * *}$ \\
& $(0.107)$ & $(0.0768)$ & $(0.509)$ \\
\hline \multirow{2}{*}{ robust } & $3.22^{* *}$ & & \\
Hausman test & {$[0.0191]$} & & \\
$\mathrm{N}$ & 248 & 248 & 248 \\
$\mathrm{R}^{2}$ & 0.644 & 0.816 & 0.621 \\
\hline
\end{tabular}

Note: ${ }^{*}, * *$ and $* * *$ indicate statistical significance at the 10,5 , and 1 percent levels, respectively. The standard error is in ( ) and the $p$ value is in [ ].

\subsection{Robustness test}

The RTS is used to replace the dependent variable. This paper use the fixed effect model to regress and the result of column 3 in Table 2 is obtained. 
It can be seen that the coefficient of the digital economy development level passed the 5\% significance level test, which indicates that the result of column 1 is robust.

\subsection{Further research}

Considering the unbalanced characteristics of China's economic development and the inconsistency of the development level of digital economy, this paper divides 31 provinces and cities into eastern, central and western regions for testing, and the fixed effect model regression results are shown in Table 3.

The results show that the coefficient of the development level of digital economy in the eastern region is significantly positive at the level of $1 \%$, while the coefficient of the development level of digital economy in the western and central regions is positive but not significant. It indicates that the development of digital economy in the eastern region plays a more significant role in promoting the upgrading of industrial structure than that in the western and central regions. The reason may be that there is a huge gap between the development level of digital economy in the central and western regions and the eastern region, and the industrial structure in the central and western regions is at a low level. Therefore, the promotion effect of the development of digital economy on the upgrading of industrial structure has not yet been reflected.

Table 3. Regression results of regional heterogeneity

\begin{tabular}{cccc}
\hline & Eastern & Central & Western \\
\hline VARIABLES & Str & Str & Str \\
\hline \multirow{2}{*}{ Dig } & $0.0174^{* * *}$ & 0.00325 & 0.000616 \\
& $(0.00330)$ & $(0.00378)$ & $(0.00134)$ \\
& $1.17 \mathrm{e}-$ & & $5.87 \mathrm{e}-$ \\
Pgdp & $06^{* * *}$ & $5.47 \mathrm{e}-06^{* * *}$ & $06^{* * *}$ \\
& $(3.24 \mathrm{e}-07)$ & $(1.11 \mathrm{e}-06)$ & $(6.50 \mathrm{e}-07)$ \\
Open & $0.0967^{* *}$ & $-0.537^{* *}$ & $0.324^{* * *}$ \\
& $(0.0381)$ & $(0.267)$ & $(0.0919)$ \\
Gov & $1.027^{* * *}$ & $0.764^{* * *}$ & $0.955^{* * *}$ \\
& $(0.181)$ & $(0.224)$ & $(0.150)$ \\
Hum & 0.0257 & 0.0361 & -0.00227 \\
& $(0.0198)$ & $(0.0337)$ & $(0.0148)$ \\
Constant & $1.831^{* * *}$ & $1.632^{* * *}$ & $1.669^{* * *}$ \\
& $(0.185)$ & $(0.292)$ & $(0.120)$ \\
\hline $\mathrm{N}$ & 88 & 64 & 96 \\
$\mathrm{R}^{2}$ & 0.784 & 0.801 & 0.695 \\
\hline
\end{tabular}

Note: ${ }^{*}, * *$, and ${ }^{* * *}$ indicate statistical significance at the 10,5 , and 1 percent levels, respectively.

In summary, the development level of digital economy has a positive role in promoting the upgrading of industrial structure. Different from previous studies, this paper considers different types of digital economy when constructing the index system of development level of digital economy. The deficiencies of this paper are: due to the inaccessibility and incompleteness of some data in the development level of various types of digital economy and the deviation of statistical caliber, the construction of the index system is limited, and considering the availability of data, the variables selected in the regression analysis are not comprehensive enough, which may have an impact on the empirical results.

\section{Conclusions}

In the period of vigorous development of digital economy, improving total factor productivity, achieving high-quality development of various industries and promoting the upgrading of industrial structure are urgent problems to be solved in China. This paper expounds the mechanism of the development of digital economy promoting the optimization and upgrading of China's industrial structure through theoretical analysis, then obtains the panel data of 31 provinces and cities in China from 2012 to 2019, and uses the method of empirical test to analyze the impact of the development of digital economy on the upgrading of China's industrial structure.

By analyzing the empirical results, this paper concludes that the development of digital economy will significantly promote the upgrading of China's industrial structure. Through further empirical test on the panel data of eastern, central and western regions, it is concluded that the development of digital economy has a significant role in promoting the optimization and upgrading of the industrial structure level in the eastern region of China, but has no significant impact on the central and western regions. This shows that under the background of unbalanced economic development in China, the development of digital economy has different effects on the upgrading of industrial structure in different regions of China, and there is regional heterogeneity. This study is of great significance for the high-quality economic development and the optimization and upgrading of industrial structure.

\section{References}

1. Zhao Xisan. (2017) Analysis on the transformation and upgrading of Chinese manufacturing driven by digital economy. Academic Journal of Zhongzhou, 36-41.

2. Jing Wenjun, Sun Baowen. (2019) Digital economy promotes high-quality economic development: a theoretical analysis framework. Economist, 66-73.

3. Jia Hui, Guo Yanan, Chu Hao, Ye Qianlin. (2020) The empirical analysis of the economic development driven by digital economy in the post-epidemic era. Journal of Industrial Technological Economics,39: 138-144.

4. Cao Zhengyong. (2018) Research on the new manufacturing model to promote high-quality development of China's industry under the background of digital economy. Theoretical Investigation, 99-104.

5. Shen Yunhong, Huang Jun. (2020) Research on influence of digital economy level on industrial 
structure optimization and upgrading of manufacturing industry: based on panel Data of Zhejiang province from 2008 to 2017. Science and Technology Management Research, 40: 147-154.

6. Zhang Xueling, Jiao Yuexia. (2017) A preliminary study of China's digital economy development index and its application. Zhejiang Social Sciences, 32$40+157$. 